\title{
A Proposed Framework for Managing Technical People in Software Projects
}

\author{
${ }^{1}$ Mohammed A. Othman, ${ }^{2}$ Sherif A. Mazen, ${ }^{3}$ Ehab Ezzat \\ ${ }^{1}$ Faculty of Computers and Information, Cairo University, Cairo, EGYPT \\ ${ }^{2}$ Assoc Prof. Information Systems Department, Cairo University \\ ${ }^{3}$ Assoc. Prof., Information Systems Department, Cairo University
}

\begin{abstract}
The human is the most significant success factor in any organization, or project. The main purpose of this research is to introduce a proposed framework for enhancing the technical team management in Information Systems (IS) projects; the proposed framework is helpful for project managers, and leads to project success, and delivered within planned time, budget, and acceptable quality. The proposed framework contains a set of components which may help to enhance the human management in software projects. Most of published studies in the area of IS projects have shown that; the technical team can be one from the most causes of the project failures[1], so we are trying to contribute in this area of IS projects management. In this research we had started to survey in IS projects management, then focused on technical team problems, such as team selection, team evaluation, tasks allocation, and study how the published researches were tried to provide solutions. After that we have collected the most significant problems, and then we developed our proposed framework. The proposed framework has overcome some of these problems. The framework covered the project life cycle phases; because the management activates extended along and cover all life cycle phases. In order to evaluate our proposed framework the evaluation processes done through a real case studies on four live IS projects in Egypt; the results of the cases study conclude that the more applying of the proposed framework, the more leading to project success.
\end{abstract}

Keywords: Software Project Management,Technical Team Management (TTM), Software Projects (SW).

\section{Introduction}

Technical team management is the very important part of projects management is SW projects [4]. Your team is the most important resource you have available and their enthusiastic contributionwill make or break your project [6]. In this research we will survey, and study how to enhance the technical team management in software projects in order to lead the project to success and delivered in time andplanned budget. Thehumanis the most significant success factor in any project, so the researches and studies in the management of human resources in softwareproject become a hot research area and important matter, alsothe published studies $[13,14,15]$ in people management in software projects show that the technical team can be one from the most causes ofProjectsfailure. A project is a temporary endeavor with a defined beginning and end (usually time-constrained and often constrained by funding or deliverables) [2].Projects Management is an Organizing, securing managing, leading, and controlling resources to achieve specific goals. Software project management is the art and science of planning and leading software projects [1]. Software projects management: it's a sub discipline of project management in which software projects are planned, monitories, and controlled. The software development methodologies, approaches, researches, and published studies till now almost interested in the software project as a final product, even in the development phases discussed only the steps of analysis, design, testing, of the software project itself.

\section{Research Scope}

This paper focuses in project management specifically in software project management, and contributes some points and aspects in technical team management this is paper is the first step for building a new framework which solve some problems in area of technical team management in software projects management.

\section{People In Software Projects}

Information Technology (IT) project Management (software project management) is a sector that has arguably witnessed the highest rate of project failure [4]. People are an organization's most important assets, the tasks of a manager are essentially to be people-oriented, unless there is some understanding of people, and management will be unsuccessful [3]. Poor people management is an important contributor to project failure [3]. According the graph below which show the people is the most important factor in software development process 


\section{Related Work}

Some methodologies and approaches interested in human factor in software development process like Agile Methodology, Rapid Application Development RAD; but there is no complete study and guides discuss and study the human factor specifically in software projects, so some studies appear to disuses only some aspects of human factor [12]. People-related issues are central factors in determining the success of software projects; indeed, many software projects fail in terms of meeting customer needs, on-time delivery, and budget. Since the importance of the human aspects of software engineering (SE) to the success of software projects has already been acknowledged, why do these aspects not receive more attention in the software industry in order to improve project results?[12].

\subsection{Planning problem :}

\section{Problems Related To Human}

Sometimes IT managers are not given the opportunity to plan because time pressure from senior management take over and most of the time the project is on its way before it has been clearly defined [6]. Detailed plans are not effective for managing IT work. The reason is that the managers do not know enough about the work to make detailed plans [11]. Team members might make their own plan but most of them do not want to. They would rather implement the solution. Few of them have the skills and experience to make complete plans, and there is a big risk in trusting them in producing their own plans that will meet management objectives [11].

\subsection{Unclear goals and objectives for the project technical teams:}

Sometimes the goal of a project may be only partially clear due to a poor requirement gathering in the definition stage of a project [7].

\subsection{Objectives changing during the project:}

Scope creep refers to uncontrolled and unexpected changes in user expectations and requirements as a project progress, while feature creep refers to uncontrolled addition of features to a system with a wrong assumption that one small feature will add nothing to cost or schedule [8].

\subsection{Estimation problem}

Assume we have a large IT project using a team with a staff of one hundred people. Linear thinking would support the conclusion that increasing the people by 100 percent would decrease the schedule and increase the cost to approximately the same degree. In reality, doubling the staff produce a non-linear result [9].

\subsection{Lack of executive support and user involvement:}

The researchers and academic institution has focused on the lack of executive support and user involvement as two main difficulties in managing IT projects [10].

\subsection{Communication problems}

Failure to communicate and act as a team

Projects sometimes fail due to improper communication. Science Application International Corporation said that the communication with FBI was difficult because of the high turnover of top IT managers [9]. Communication problems are common on large IT projects. Because complex IT projects often involve large amount of analysis and work, the project teams are busy and the executive management sees no progress. IT project managers do not communicate progress regularly because they believe that progress will not be seen by the executive management [7].

\subsection{Inappropriate skills:}

The challenge of global competition, the rapid growth of knowledge, and the constant changes of technology make it hard to predict what kind of skilled people will be needed.

Most IT projects require a diverse range of skills. Many teams lack the breadth, and depth they require[1][8]. It is also not easy for technology based organization to find the experienced people they need because sometimes few people in the labor market have the necessary skills.

The larger the project, the more need there is also for people with excellent planning, oversight, organization, and communications skills; experienced technology skilled people do not necessarily have these abilities [7]. 


\subsection{Project Team Preparation\& Evaluation}

\section{First Step In Our Proposed Framework}

After we have built team structure and decompose the project goals into some objectives which will also divided into small manageable tasks or deliverables we must ensure and review our team members using a new component we have added it to this framework (Task- skill(s) needed Matrix) we will explain it in the following part the propose of this matrix that will detect a lack of knowledge, and weakness of our team members,and help us to assign the right task to right member.

\subsubsection{Skills and Competencies Determination}

How we can determine and recognize tam member's skills? The answer of this question is very importantbecause we can't assign and allocate the tasks to right persons if we not sure this person has needed skills to complete, finish this task; so we need to follow a guide to help us to determine the team member's skills based on some Evaluation criteria's.

In our proposed framework we develop a (Skill-Criteria' Matrix) this matrix listed a two dimension the first one set of skills, recognized by asset of criteria's e.g. a person has a skill "fix bugs which appears in integration test stage" this member skill detected or evaluated by some criteria's like years of Experience in this role" Integration test", standard certifications in Software testing, number of projects he/she has done, etc. So the skills- criteria matrix evaluation will be very helpful to ensure the task assignment will be well done and the right task for right person, that is will explained as the following table show[1]:

\subsection{Team Classification}

The first step we will classify our software team members into a business, and technical group according to knowledge level, skills and mentality, years of experiences, qualifications \& Certifications, and functional classification; like consultants, developers , and designers.

\subsection{Technical Team Structuring:}

Build a clear and general structure for SW Project Team, which represents the hierarchical view and related blocks and reporting structure.

\subsection{Decompose The Project Activities into Manageable Parts:}

According to the team members classification, project goals and objectives, and business requirements; we jump to decompose the project into set of manageable parts,tasks, and deliverables.After the rightdecomposition done we start to tasks assignment and allocation, according to the team classification and groups. The classification of team will done based on different criteria's like qualifications, certifications, years of experience in similar working area, and nature of the task oractivity.

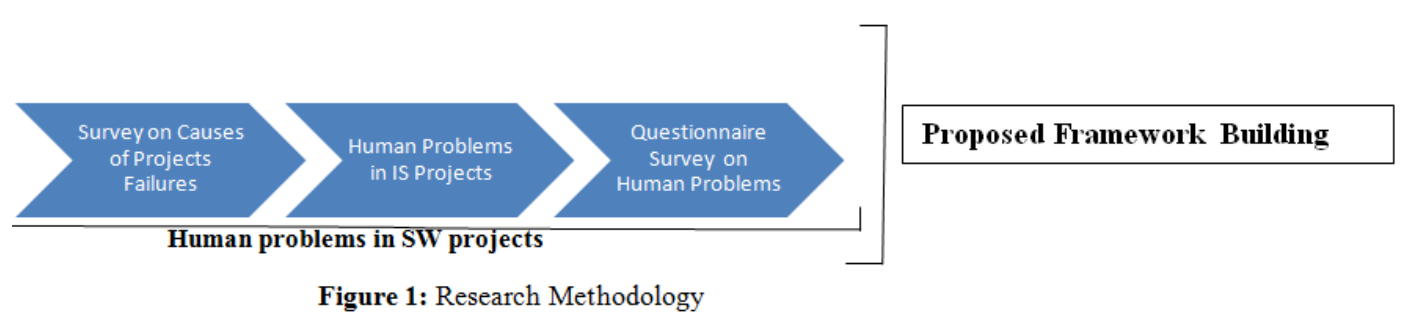

\section{Research Methodology:}

- Survey in most related topics in HR management, and IS projects.

- Questionnaire designed for data \& information collection from 30 experts to build the proposed framework.

- Building the proposed framework.

- Framework evaluation by four case studies in a real is projects in the market

- Analysis the result and write the conclusion result

VII. Abstrac View Of Our Proposed Framework

The following graph isrepresenting the proposed framework components: 


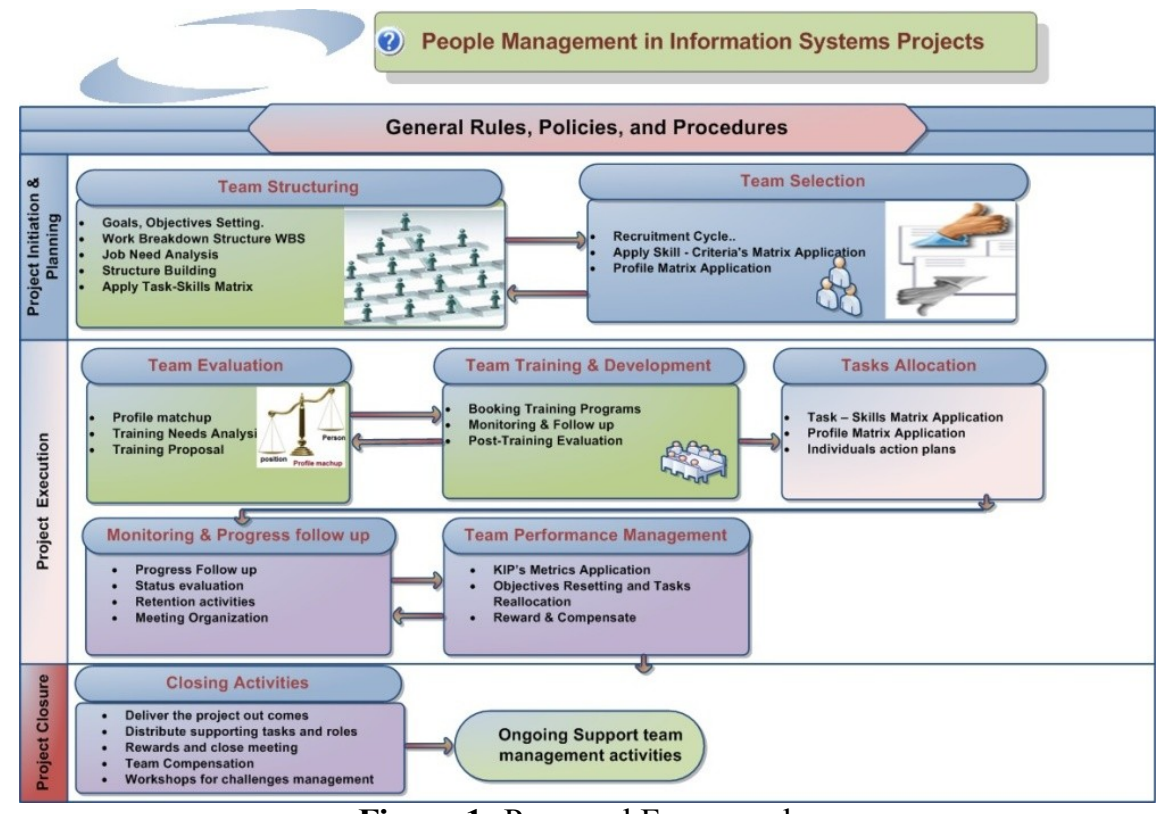

Figure 1: Proposed Framework

VIII. Framework Evaluation

Through this research we have developed an evaluation and assessment method;it'sa cases study on four live projects in the market. The case studies divided the framework into a lot of concepts behind all activities and rules in the framework (items); then we have studied whether these items applied or not, and what is the percentage of applying or not applying of this frameworks items. Also studied what are the effects of deviation from framework application on some selected impact factors.

The case studies were concluded that the more applying of the proposed framework, the more leading to project success, and the more applying of proposed framework, the more human problems overcome.

\section{Impact Factors on the projects regarding the framework application deviation}

\begin{tabular}{|c|}
\hline Impact Factors on the project \\
\hline i1:Project Cost \\
\hline i2: Project Duration \\
\hline i3: Manpower size \\
\hline i4: Team Turnover \\
\hline i5: Quality of Deliverables \\
\hline i6: Managerial Issues \\
\hline i7: Technical Issues \\
\hline i8: Business Issues \\
\hline i9: Resources Utilization \\
\hline i10: Responsibilities Interference \\
\hline i11: Team moral, personal Satisfaction \\
\hline i12: Lack of Skills \\
\hline
\end{tabular}

Table 1: Impact Factors of or Evaluation

\section{Case Studies And Discussion}

In order to investigate our proposed framework we decided to apply our framework in a four real Software projects in Egypt. The researcher has developed a sixty three items or concepts behind the framework; which reflect the concepts behind the proposed framework components and activities. Then we met managers, larders, and key parsons in each project. Then asked them to answer the questionnaire, the questionnaire covered all the sixty three impact factors of our proposed framework.

We can observe through the applied study in all four projects; the more applying of the framework concepts the more leading to success. 


\section{- Framework Application and Project Success:}

According to the case study results which conclude that the more applying of the proposed framework concepts, the more leading to success; also this is clear from the result the fewest negative impact in the project factors it is the project with the highest value of framework application(79.8\%). human factor.

Also during the case study we notice that the project 3 is the smallest deviation and problems related to

\section{Abstract view of proposed framework}

\begin{tabular}{|c|c|c|c|c|c|c|c|c|c|c|c|c|c|}
\hline Project & FW Application \% & i1 & i2 & i3 & i4 & i5 & i6 & i7 & i8 & i9 & i10 & i11 & i12 \\
\hline P1 & $60.0 \%$ & $44.4 \%$ & $51.1 \%$ & $24.4 \%$ & $21.3 \%$ & $34.0 \%$ & $34.3 \%$ & $41.0 \%$ & $17.8 \%$ & $42.9 \%$ & $32.1 \%$ & $38.1 \%$ & $47.6 \%$ \\
\hline $\mathbf{P 2}$ & $75.0 \%$ & $35.6 \%$ & $40.9 \%$ & $19.6 \%$ & $17.0 \%$ & $27.2 \%$ & $27.5 \%$ & $32.8 \%$ & $14.2 \%$ & $34.3 \%$ & $25.7 \%$ & $30.5 \%$ & $38.1 \%$ \\
\hline P3 & $79.8 \%$ & $27.9 \%$ & $32.1 \%$ & $15.4 \%$ & $13.4 \%$ & $21.3 \%$ & $21.5 \%$ & $25.7 \%$ & $11.2 \%$ & $26.9 \%$ & $20.1 \%$ & $23.9 \%$ & $29.9 \%$ \\
\hline P4 & $70.0 \%$ & $44.0 \%$ & $50.6 \%$ & $24.2 \%$ & $21.1 \%$ & $33.6 \%$ & $33.9 \%$ & $40.5 \%$ & $17.6 \%$ & $42.4 \%$ & $31.7 \%$ & $37.7 \%$ & $47.1 \%$ \\
\hline $\mathrm{CS}$ & $71.2 \%$ & $38.0 \%$ & $43.7 \%$ & $20.9 \%$ & $18.2 \%$ & $29.0 \%$ & $29.3 \%$ & $35.0 \%$ & $15.2 \%$ & $36.6 \%$ & $27.4 \%$ & $32.6 \%$ & $40.7 \%$ \\
\hline
\end{tabular}

Table 2: Projects Application Results with indicators

Case Studies Results:

Notethe symbols in the table above; i1, i2 .. i12meaning in the impact factors indicated in table1

\section{Framework Application Percentage in all projects:}

\begin{tabular}{|l|r|}
\hline Project & Framework Application \% \\
\hline Project1 & $60.0 \%$ \\
\hline Project2 & $75.0 \%$ \\
\hline Project3 & $79.8 \%$ \\
\hline Project4 & $70.0 \%$ \\
\hline Case Study & $71.2 \%$ \\
\hline
\end{tabular}

Table 3: Framework application by project

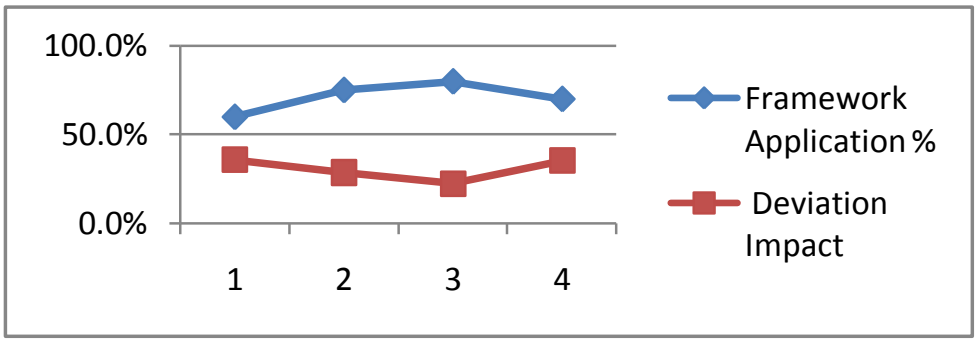

Figure 2: Framework Application and Deviation Impact

According to the case studies results we conclude that the more applying of the proposed framework concepts, the more leading to success; also this is clear from the result the fewest negative impact in the project factors it is the project with the highest value of framework application(79.8\%). human factor

Also during the case study we notice that the project 3 is the smallest deviation and problems related to

\section{Conclusion}

This research introduces a proposed framework to enhance the technical team management in IS projects. Because the poor management of technical people sometimes may be the main causes of project failure. the proposed framework that we have developed in this research enhance the management of technical teams by a set of rules and guidance that project manager or team leader if they follow this guide it will be helpful and contribute in IS project success

The proposed framework contains a set of components which described by a set of guides and rules recommended to followed in technical people management.

This research provides an additional insight into the link between management of teams and IS project life cycle as whole and indicates that there is a strong link between human Management and IS project success. From a 
practitioners' perspective this research highlights to IS projects managers in how they can manage their team in right manner and guide the project to success.

The proposed framework is helpful for project managers, and leads to project success, and delivered within planned time, budget, and acceptable quality. The proposed framework has introduced a set of components which may help to enhance the human management in software projects. Most of published studies in the area of IS projects have shown that; the technical team can be one from the most causes of the project failures[2], so we are trying to contribute in this area of IS projects management. In this research we had started to survey in IS projects management, then focused on technical team problems, such as team selection, team evaluation, tasks allocation, and study how the published researches were tried to provide solutions. The proposed framework evaluated through four real case studies in four IS projects in the market, the studies shown that the more applying the proposed concepts behind this framework, the more leading to project success and human problems overcoming.

\section{Future Works}

During this research we notice that some points needs to make a complete study and add a new procedures and techniques to enhance and improve the management of technical people in software projects, this points like tasks allocation and distribution, team members Evaluation, and selection criteria based on some standards and certifications, also we need to develop a maturity model for people skills and competencies evaluation and measurements.

[1] MindTools.com. 10 Common Time Management Mistakes Avoiding Common Pitfalls Available: http://www.mindtools.com/pages/article/time-management-mistakes.htm\#sthash.vmkpaYa6.dpuf

[2] I. m. article. (2012) "Why Software Fails". IEEE. Available: http://spectrum.ieee.org/computing/software/why-software-fails/3

[3] I. Sommerville. (2011). Software engineering (Ninth Edition ed.).

[4] A Guide To The Project Management Body Of Knowledge (PMBOK Guides): Project Management Institute, 2004.

[5] F. Heyworth and E. C. f. M. Languages, A Guide to Project Management: Council of Europe Publishing, 2002.

[6] I. m. article. (2012) "Why Software Fails". IEEE. Available: http://spectrum.ieee.org/computing/software/why-software-fails/3

[7] I. Nutek, "Project Management Body of Knowledge " PMI, Project Management Institute, vol. ISBN: 1-880410-23-0(2000 Edition).

[8] I. Sommerville, SOFTWARE ENGINEERING. Addison- Wesley: Pearson Education, Inc.,, 2011.

[9] D. E. New Zealand "analytical comparison of five agile methods and an investigation of their target environment " university of Massey, 2005

[10] A. D. Cassandro Hamel, Sandra Safran , Andrée Clément, "compensation guide:A manual on compensation Practice \& $\neg$ theory," vol. N 978-0-9680721-7-2 March, 2008.

[11] A. Cockburn, "Characterizing People as Non-Linear, First-Order Components in Software Development," ed, 2005.

[12] R. P. Institute. (2008). Human Resource Policy Guidelines.

[13] O. Hazzan and J. Tomayko, "Human Aspects of Software Engineering: The Case of Extreme Programming," in Extreme Programming and Agile Processes in Software Engineering. vol. 3092, J. Eckstein and H. Baumeister, Eds., ed: Springer Berlin Heidelberg, 2004, pp. 303-311. 